\title{
Seiche excitation in a highly stratified fjord of southern Chile: the Reloncaví fjord
}

\author{
Manuel I. Castillo ${ }^{1,2}$, Oscar Pizarro ${ }^{2,3,4}$, Nadin Ramírez $^{2,4}$, and Mario Cáceres ${ }^{1}$ \\ ${ }^{1}$ Escuela de Biología Marina, Facultad de Ciencias del Mar y de Recursos Naturales, \\ Universidad de Valparaíso, Valparaíso, Chile \\ ${ }^{2}$ COPAS-Sur Austral, Universidad de Concepción, Concepción, Chile \\ ${ }^{3}$ Departamento de Geofísica, Universidad de Concepción, Concepción, Chile \\ ${ }^{4}$ Instituto Milenio de Oceanografía, Universidad de Concepción, Concepción, Chile \\ Correspondence to: Manuel I. Castillo (manuel.castillo@uv.cl)
}

Received: 7 June 2016 - Discussion started: 7 July 2016

Revised: 25 January 2017 - Accepted: 27 January 2017 - Published: 17 February 2017

\begin{abstract}
We describe a seiche process based on current, temperature, and sea-level data obtained from the Reloncaví fjord $\left(41.6^{\circ} \mathrm{S}, 72.5^{\circ} \mathrm{W}\right)$ in southern Chile. We combined 4 months of acoustic Doppler current profiler (ADCP) data with sea-level, temperature, and wind time series to analyze the dynamics of low-frequency (periods $>1$ day) internal oscillations in the fjord. Additionally, seasonal conductivity, temperature, and depth (CTD) data from 19 along-fjord stations were used to characterize the seasonality of the density field. The density profiles were used to estimate the internal long-wave phase speed (c) using two approximations: (1) a simple reduced gravity model (RGM) and (2) a continuously stratified model (CSM). No major seasonal changes in $c$ were observed using either approximation (e.g., the CSM yielded $0.73<c<0.87 \mathrm{~m} \mathrm{~s}^{-1}$ for mode 1$)$. The natural internal periods $\left(T_{\mathrm{N}}\right)$ were estimated using Merian's formula for a simple fjord-like basin and the above phase speeds. Estimated values of $T_{\mathrm{N}}$ varied between 2.9 and 3.5 days and were highly consistent with spectral peaks observed in the alongfjord currents and temperature time series. We conclude that these oscillations were forced by the wind stress, despite the moderate wind energy. Wind conditions at the end of winter gave us an excellent opportunity to explore the damping process. The observed damping time $\left(T_{\mathrm{d}}\right)$ was relatively long $\left(T_{\mathrm{d}}=9.1\right.$ days $)$.
\end{abstract}

\section{Introduction}

Internal seiche oscillation has long been known in closed basin geometries (e.g., Watson, 1904; Wedderburn, 1907; Wedderburn and Young, 1915). The first detailed description thereof was presented by Mortimer (1952). In these systems, wind is the main force affecting the surface and isotherms (Wiegand and Chamberlain, 1987), which produces a set of periodic oscillations and circulation cells throughout the water column that may contribute to internal mixing of the basin (Thorpe, 1974; Monismith, 1985; Wiegand and Chamberlain, 1987; Münnich et al., 1992; Mans et al., 2011; Simpson et al., 2011).

Although external (barotropic) seiches are ubiquitous in closed basin geometries (Münnich et al., 1992), it is not theoretically evident that there are internal seiches (baroclinic) in a linearly stratified fluid (Maas and Lam, 1995). It is possible to find resonant basin modes, but only in wellbehaved geometries (Arneborg and Liljebladh, 2001a). However, studies of lakes have yielded good results using layered models (e.g., Lemmin, 1987), normal-mode approximations (e.g., Wiegand and Chamberlain, 1987; Münnich et al., 1992), or numerical model simulations (e.g., Goudsmit et al., 2002). In fact, internal seiches have been observed in semienclosed systems such as fjords (e.g., Djurfeldt, 1987; Pasmar and Stigebrandt, 1997; Arneborg and Liljebladh, 2001a) with complex geometries and where linear stratification is rarely observed, and thus the only way to maintain consistency with the theory is that the oscillation in the pycnocline 
Table 1. Characteristics of the Reloncaví fjord. The name, mean depth $(H)$, and length $(L)$ of each sub-basin and for the entire fjord are presented.

\begin{tabular}{llrr}
\hline Sub-basin & Description & $H(\mathrm{~m})$ & $L(\mathrm{~km})$ \\
\hline I & mouth-Marimeli & 440 & 14.0 \\
II & Marimeli-Puelo & 250 & 13.0 \\
III & Puelo-Cochamo & 200 & 17.5 \\
IV & Cochamo-head & 82 & 10.5 \\
\hline \multirow{2}{*}{ Total } & mouth-head & 250 & 55 \\
\hline
\end{tabular}

dominates the internal seiche oscillation (Arneborg and Liljebladh, 2001a). Early in the development of a seiche, its amplitude is related to the forcing intensity, and the standing oscillation then becomes free and requires no additional forcing. The frequencies are retained, but the amplitude decays (damping) exponentially due to friction until the system comes to rest (Rabinovich, 2010). The development of seiche oscillations depends on the forcing and damping mechanisms; with large damping, it is impossible to observe a seiche, whereas small damping of a seiche allows for several oscillations (Arneborg and Liljebladh, 2001a).

In fjords with shallow sills, the interaction between the sill and the barotropic tide generates internal tides that are more energetic than other internal oscillations and are the focus of most studies regarding mixing and internal oscillations based on internal tides (e.g., Stigebrandt, 1980; Stigebrandt and Aure, 1989; Inall and Rippeth, 2002; Ross et al., 2014). In the case of fjords with a deep sill and low tidal energy, the breaking of the internal seiche oscillations at the boundaries could be an important contributor to the internal mixing, promoting the spreading of properties within the fjord, particularly in deep waters (Stigebrandt and Aure, 1989; Münnich et al., 1992; Arneborg and Liljebladh, 2001b). Additionally, there is evidence that vertical isopycnal displacements in fjords could be generated by similar displacements outside the fjord (e.g., Svensen, 1980; Djurfeldt, 1987). These remotely generated oscillations could enhance the mixing and ventilation in deep fjords.

There is still only limited understanding of the main oceanographic processes occurring in the fjord region of southern Chile, although there has been local research during the previous few decades. Since early studies of the hydrography by Pickard (1971), a systematic measurement program in the fjord region has been maintained since 1995 (Palma and Silva, 2004; Pantoja et al., 2011; Iriarte et al., 2014), although only a small number of studies have focused on the physical dynamics. Most studies have been conducted over short time spans (e.g., Cáceres et al., 2002; Valle-Levinson et al., 2007), and only a few studies have been based on more than 1 month of data (e.g., Letelier et al., 2011; Castillo et al., 2012; Schneider et al., 2014), thereby limiting our understanding of sub-inertial variability. In the Reloncaví fjord, time series of approximately 4 months have shown evidence that 3-day oscillations of currents could be produced by internal seiche oscillations (Castillo et al., 2012), but lack a description of the forcing mechanism and the seasonal modulation.

This study presents the first evidence of internal seiche oscillations in a fjord in southern Chile. The objective of this study was to address how these oscillations affect the temporal and spatial dynamics of currents and temperature, and how these oscillations are forced.

\section{Study area}

The Reloncaví fjord $\left(41.5^{\circ} \mathrm{S}, 72.5^{\circ} \mathrm{W}\right)$ is the northernmost fjord on the coast of Chile (Fig. 1). This "J"-shaped fjord is $55 \mathrm{~km}$ long and has a width that varies from $3 \mathrm{~km}$ near the mouth to $1 \mathrm{~km}$ near the head. There is a deep sill $(\sim 200 \mathrm{~m}$ depth) located $15 \mathrm{~km}$ inland, although it does not appear to be a barrier to the exchange of properties between the adjacent basins. Based on bathymetric features and the coastline morphology, this fjord can be separated into four sub-basins displaying the characteristics presented in Table 1 and Fig. 2.

The main river discharge is provided by the Puelo River (at the middle of the fjord), which produces a mean annual discharge of $650 \mathrm{~m}^{3} \mathrm{~s}^{-1}$. The Petrohue River (at the head of the fjord) has an mean annual discharge of $255 \mathrm{~m}^{3} \mathrm{~s}^{-1}$, and there are additional freshwater inputs of minor importance compared with the Cochamo River (mean annual discharge of $20 \mathrm{~m}^{3} \mathrm{~s}^{-1}$ ) and the Canutillar hydroelectrical plant (mean annual discharge $75.5 \mathrm{~m}^{3} \mathrm{~s}^{-1}$; Niemeyer and Cereceda, 1984). The freshwater input to the fjord due to direct precipitation is only approximately $2 \%$ of the main river discharge (LeónMuñoz, 2013), and its contribution may be in balance with evaporation (Castillo et al., 2016). The freshwater input creates a marked along-fjord pycnocline that is deeper at the head $(\sim 8 \mathrm{~m})$ and shallower at the mouth $(\sim 3 \mathrm{~m}$; Fig. 2$)$.

During the winter, the mean wind stress $(\tau)$ is low due to calm winds $\left(<10^{-3} \mathrm{~N} \mathrm{~m}^{-2}\right)$. During storm events in winter, $\tau$ can reach values as high as $0.4 \mathrm{~N} \mathrm{~m}^{-2}$ (winds of $>10 \mathrm{~m} \mathrm{~s}^{-1}$ ), and the wind tends to blow out of the fjord, thereby reinforcing the upper outflow of brackish water. In contrast, during the spring/summer, the winds exhibit a marked diurnal cycle, and $\tau$ can reach values as high as those observed in the winter, whereas the wind blows landward, i.e., toward the fjord's head and against the upper flow. Tides in the Reloncaví fjord are predominantly semi-diurnal, and during spring the tidal range never exceeds $6 \mathrm{~m}$, whereas the neap tidal range is about $2 \mathrm{~m}$. The tidal current is relatively weak in the upper layer, which is dominated by gravitational circulation (ValleLevinson et al., 2007; Montero et al., 2011; Castillo et al., 2012). 


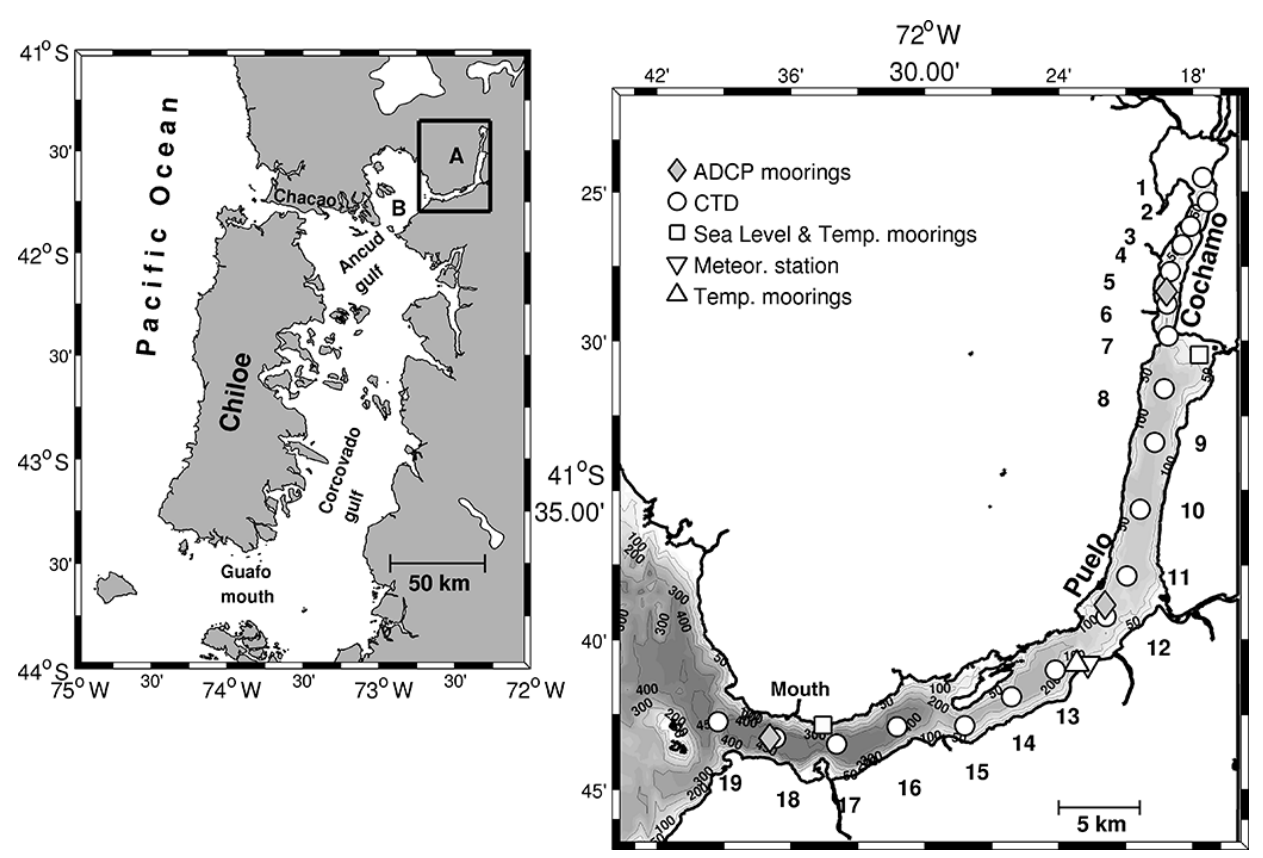

Figure 1. Study region and location of the measuring stations. The left panel shows the area of the Reloncaví fjord (a). The location of the Reloncaví sound (b) is also shown. The right panel shows the study area (close-up view of a) and the positions of all measurements. Numbers are CTD stations.

\section{Data and methods}

\subsection{Field observations}

Current measurements were obtained using Teledyne RD Instruments acoustic Doppler current profiler (ADCPs) in three subsurface mooring systems. These subsurface systems were located near the fjord mouth, near the Puelo River and between the Cochamo and Petrohue rivers (Fig. 1). The longest time series spanned the period of August through November 2008 (Fig. 1 and Table 1). At the mouth, two upward-looking ADCPs were positioned at nominal depths of $10(300 \mathrm{kHz})$ and $450 \mathrm{~m}(75 \mathrm{kHz})$. The Puelo mooring held two ADCPs, one facing up at a depth of $30 \mathrm{~m}(600 \mathrm{kHz})$ and one facing downward at a depth of $35 \mathrm{~m}(300 \mathrm{kHz})$. The Cochamo mooring held one facing-up ADCP at a depth of $11 \mathrm{~m}(300 \mathrm{kHz})$. Note that due to the large tidal range, the depths of the ADCPs significantly changed with the tides. These effects along with small vertical deviations of the ADCPs related to the line movements - were corrected using the ADCPs' pressure sensors, and all of the bin depths were referenced to the water surface level. The mooring systems were designed to obtain the best vertical resolution available with emphasis on the upper layer. The ADCP cell sizes were $0.5(600 \mathrm{kHz})$, $1(300 \mathrm{kHz})$, and $4 \mathrm{~m}(75 \mathrm{kHz})$, and the data-acquisition time intervals were $10 \mathrm{~min}$ in most of the ADCPs, with the exception of the deepest ADCP, which was set to acquire data at an interval of $20 \mathrm{~min}$. All the ADCP configurations maintain a standard deviation of $<2 \mathrm{~cm} \mathrm{~s}^{-1}$ (details in Supplement Table S2).

The morphology of the fjord exhibits a sharp bend in the middle, and thus the $x$ and $y$ components of the currents were rotated to the local orientation of the along-fjord axis (Fig. 1 and Table 1). A right-handed coordinate system with a positive-up $z$ axis and an along-fjord $y$ axis (positive toward the fjord head) was used. Consequently, the cross-fjord $x$ component was positive toward the south (east) near the fjord mouth (head). To assess the contribution of the tides to the currents, the amplitudes and phases of several tidal components were calculated at all of the moored ADCPs using a standard harmonic analysis from Pawlowicz et al. (2002).

The vertical structure of the temperature was obtained from Onset HOBO-U22 temperature sensors installed in three mooring systems along the fjord (Fig. 1). These moorings held surface buoys supporting the thermistor chains with an anchor located at a $25 \mathrm{~m}$ depth to maintain their nominal depths $(0,1,2,3,4,5,7,9,11,13,15$, and $20 \mathrm{~m})$ from the surface independent of tidal fluctuations. Temperature data were collected every $10 \mathrm{~min}$ at all locations.

A Davis Vantage Pro2 meteorological station was installed south of the Puelo River (see Fig. 1). This station held sensors for measuring the wind direction and velocity, solar radiation, rain, and air temperature. The wind magnitude and direction sensors were installed $10 \mathrm{~m}$ above sea level and were set to collect data every $10 \mathrm{~min}$ from 12 June 2008 to 30 March 2011. Gaps in the time series represented only $0.04 \%$ of the total data. The wind stress $(\tau)$ was calculated using a 
Table 2. Seasonal statistics of the descriptive parameters of the fjord. Here we present the mean depth of the upper layer $\left(h_{1}\right)$ and densities of the upper $\left(\rho_{1}\right)$ and deep layers $\left(\rho_{2}\right)$. In addition, the phase and modal velocities $(c)$ and their periods $(T)$ estimated using the reduced gravity and continuously stratified models are shown.

\begin{tabular}{|c|c|c|c|c|c|c|}
\hline \multicolumn{7}{|c|}{ Reduced gravity model (RGM) } \\
\hline & $\begin{array}{r}h_{1} \\
(\mathrm{~m})\end{array}$ & $\begin{array}{r}\rho_{1} \\
\left(\mathrm{~kg} \mathrm{~m}^{-3}\right)\end{array}$ & $\begin{array}{r}\rho_{2} \\
\left(\mathrm{~kg} \mathrm{~m}^{-3}\right)\end{array}$ & $\begin{array}{r}c \\
\left(\mathrm{~ms}^{-1}\right)\end{array}$ & $\begin{array}{r}T \\
\text { (days) }\end{array}$ & \\
\hline Winter & $4.60 \pm 0.60$ & $1009.72 \pm 4.32$ & $1024.62 \pm 0.74$ & $0.76 \pm 0.01$ & $3.37 \pm 0.03$ & \\
\hline Spring & $4.79 \pm 0.53$ & $1007.63 \pm 5.32$ & $1024.78 \pm 0.62$ & $0.87 \pm 0.02$ & $2.92 \pm 0.03$ & \\
\hline Summer & $4.68 \pm 0.26$ & $1008.77 \pm 3.26$ & $1024.78 \pm 0.63$ & $0.83 \pm 0.01$ & $3.07 \pm 0.02$ & \\
\hline Autumn & $4.05 \pm 0.41$ & $1009.90 \pm 3.92$ & $1024.95 \pm 0.48$ & $0.75 \pm 0.01$ & $3.38 \pm 0.03$ & \\
\hline \multicolumn{7}{|c|}{ Continuous stratified model (CSM) } \\
\hline & $\begin{array}{r}c_{1} \\
\left(\mathrm{~m} \mathrm{~s}^{-1}\right)\end{array}$ & $\begin{array}{r}c_{2} \\
\left(\mathrm{~ms}^{-1}\right)\end{array}$ & $\begin{array}{r}c_{3} \\
\left(\mathrm{~ms}^{-1}\right)\end{array}$ & $\begin{array}{r}T_{1} \\
\text { (days) }\end{array}$ & $\begin{array}{r}T_{2} \\
\text { (days) }\end{array}$ & $\begin{array}{r}T_{3} \\
\text { (days) }\end{array}$ \\
\hline Winter & $0.73 \pm 0.11$ & $1.46 \pm 0.21$ & $2.18 \pm 0.32$ & $3.50 \pm 0.25$ & $1.75 \pm 0.13$ & $1.17 \pm 0.08$ \\
\hline Spring & $0.87 \pm 0.10$ & $1.73 \pm 0.21$ & $2.59 \pm 0.31$ & $2.94 \pm 0.18$ & $1.47 \pm 0.09$ & $0.98 \pm 0.06$ \\
\hline Summer & $0.84 \pm 0.07$ & $1.68 \pm 0.13$ & $2.52 \pm 0.20$ & $3.03 \pm 0.12$ & $1.51 \pm 0.06$ & $1.01 \pm 0.04$ \\
\hline Autumn & $0.77 \pm 0.08$ & $1.54 \pm 0.15$ & $2.32 \pm 0.23$ & $3.30 \pm 0.16$ & $1.65 \pm 0.08$ & $1.10 \pm 0.05$ \\
\hline
\end{tabular}

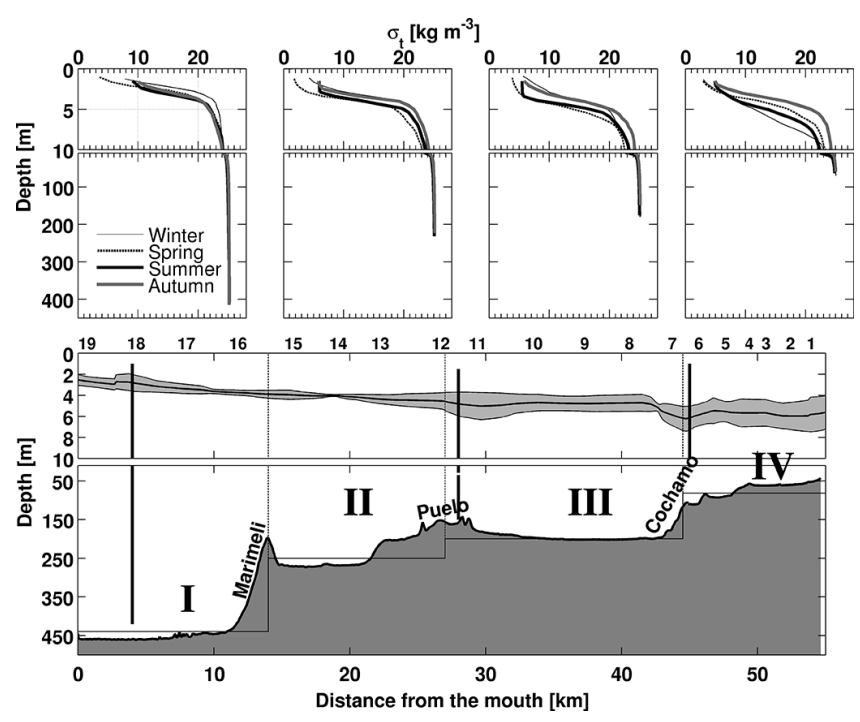

Figure 2. Seasonal profiles of density and bathymetry of the region. The upper panel shows the seasonal mean density profiles in each sub-basin of the fjord (a-d). In the panel below (e), the along-fjord bathymetry and sub-basin nomenclature are shown. The black line represents the mean pycnocline depth, and corresponding standard deviations are represented by the gray shading.

drag coefficient dependent on the magnitude (see Large and Pond, 1981) and a constant air density of $1.2 \mathrm{~kg} \mathrm{~m}^{-3}$.

The salinity and temperature profiles were obtained seasonally using a CTD SeaBird SBE 25 at 19 stations in the along-fjord transect shown in Fig. 1. The data were processed following the standard protocol suggested by the manufacturer and were averaged in vertical intervals of $0.5 \mathrm{~m}$. Due to large salinity changes in the upper layer, the instrument pump was set to a time interval of $1 \mathrm{~min}$. After the start of the pumping, the instrument was maintained near the surface until the sensors stabilized. Then, the CTD was lowered to the maximum depth of the station (Table 2). The along-fjord transects typically required 12 to $24 \mathrm{~h}$ to complete, depending on local weather conditions. Due to technical limitations, the winter transect was performed to a maximum depth of $50 \mathrm{~m}$.

The sea level was recorded every $10 \mathrm{~min}$ using two pressure sensors moored over the seabed. At Cochamo, the pressure sensor was an Onset HOBO-U20, whereas a SeaBird wave-tide gauge (SBE-26) was installed near the fjord's mouth (Fig. 1). Subsurface pressure data were corrected for air pressure and converted to an adjusted sea level.

Discharge data were provided by Dirección General de Aguas, Chile (2016). These data are regularly collected at a station located $12 \mathrm{~km}$ upstream of the Puelo River's mouth (Fig. 1). The time series extended from January 2003 to December 2011 , and data gaps represented only $2 \%$ of the total.

\subsection{Time series analysis}

Previous findings (Castillo et al., 2012) have shown an important oscillation with a period of approximately 3 days (72 h). To focus the study on these perturbations, the time series of currents and temperature were band-pass filtered using a cosine-Lanczos with half amplitudes at 60 and $100 \mathrm{~h}$ (see the results for the justification of the selected band). As part of the results, the band-passed time series of the current (Fig. 6) and temperature (Fig. 9) data are shown.

Spectral analyses of the current, wind stress, sea-level, and temperature time series were performed using Welch's modified average periodograms (Emery and Thomson, 1998). To 
achieve statistical reliability of the spectral estimations, each time series was divided into non-overlapping segments to generate spectral estimates. In the case of the current time series, the spectra were (additionally) averaged among depth layers to obtain 12,24 , and 48 degrees of freedom, depending on the frequency (see Fig. 3). In addition, to evaluate the consistency of the periodicity between the time series, we calculate a Morlet cross-wavelet analysis following wavelet methods explained by Torrence and Compo (1998) and Grinsted et al. (2004).

The phase velocity $(c)$ was estimated using two models that took into account the fjord stratification: (1) a simple reduced-gravity model (RGM) and (2) a continuously stratified model (CSM).

The reduced-gravity model was developed using the typical density profiles in each sub-basin. Here, the base of the upper layer was estimated from the pycnocline depth (Fig. 2), which in the Reloncaví fjord is well represented by the depth of the 24 isohaline ( $h_{1}$; Castillo et al., 2016), considering that $h_{1}$ is the pycnocline depth and $H$ is the deepest CTD cast (mostly near to the sub-basins' maximum depths). The mean density of the upper layer $\left(\rho_{1}\right)$ was estimated from depths between the surface and $h_{1}$, whereas the mean density for the deep layer $\left(\rho_{2}\right)$ was estimated for depths between $h_{1}$ and $H$. These estimations were made for all sub-basins and seasons (Table 2).

Using both densities, $\rho_{1}$ and $\rho_{2}$, the reduced gravity $\left(g^{\prime}=\right.$ $\left.g\left(\rho_{2}-\rho_{1}\right) / \rho_{2}\right)$ was obtained; here $g$ is the acceleration of gravity. The internal phase velocity of each sub-basin, $c_{i}=$ $\left(g^{\prime} h_{1 i}\right)^{1 / 2}$, where $i=1$ to 4 and $h_{1 i}$ represents the mean depth of the upper layer in the sub-basin " $i$ ", was used to estimate the effective phase speed in the entire fjord (Eq. 1),

$c=L \sum_{i=1}^{n} \frac{c_{i}}{L_{i}}$

where $L_{i}$ is the $i$ sub-basin length and $L$ is the fjord length. This takes into account the changes in depths and lengths of the fjord's sub-basins. Similarly, the effective period $(T)$ was obtained by $T=c L^{-1}$.

The continuously stratified model (CSM) was developed using the normal mode analysis, which introduced the stratification as $N^{2}=-(g / \rho)(\partial \rho / \partial z)$, which is the buoyancy frequency, in the Sturm-Liuoville expression

$\frac{d}{\mathrm{~d} z}\left(\frac{1}{N^{2}} \frac{d \psi_{n}}{\mathrm{~d} z}\right)+\frac{1}{c_{n}^{2}} \psi_{n}=0$

where $\psi_{n}(z)$ is the vertical structure of the horizontal velocity for the mode $n$. Here $c_{n}$ represents the $n$ mode speed (see Gill, 1982) and differs significantly from phase speed if rotation plays a role (van der Lee and Umlauf, 2011).

Independent of the model used to obtain the phase speed (RGM or CSM), the natural oscillation period $\left(T_{\mathrm{N}}\right)$ was determined using Merian's formula for a semi-enclosed basin, as suggested by Rabinovich (2010), $T_{\mathrm{N}}=4 T$.
The modal decomposition was used to obtain the contribution of each mode in the current variability (e.g., Emery and Thomson, 1998; Gill, 1982; van der Lee and Umlauf, 2011). The along- and cross-fjord band-pass currents $\left[u_{\mathrm{bp}}\right.$, $v_{\text {bp }}$ ] could be described by the vertical modes by Eq. (3),

$\left[u_{\mathrm{bp}}, v_{\mathrm{bp}}\right](z, t)=\sum_{n=1}^{\infty}\left[u_{\mathrm{pj}}, v_{\mathrm{pj}}\right](t) \psi_{n}(z)$

The along- and cross-fjord currents projected $\left(u_{\mathrm{pj}}, v_{\mathrm{bp}}\right)$ on the vertical modal structure $(\psi n)$ were obtained by Eq. (4):

$\left[u_{\mathrm{pj}}, v_{\mathrm{pj}}\right](t)=\frac{1}{H} \int_{-H}^{0}\left[u_{\mathrm{bp}}, v_{\mathrm{bp}}\right](z, t) \psi_{n}(z) \mathrm{d} z$.

\section{Results}

\subsection{Density structure}

As a result of abundant freshwater input to the fjord, there were marked differences in density between the upper and lower layers along the fjord and small changes in stratification among seasons, particularly near the mouth of the fjord (Fig. 2). One important characteristic of the upper layer is its high and persistent stratification from the surface to the base of the pycnocline (Fig. 2). Along the fjord, the pycnocline depth exhibited clear deepening from $2.3 \pm 0.1$ at the mouth to $6.1 \pm 0.3 \mathrm{~m}$ near the head. The pycnocline depth exhibited greater seasonal variability near the head of the fjord (Fig. 2).

\subsection{Winds, sea-level, and freshwater discharge}

The along-fjord wind stress $(\tau)$ displayed two patterns during the transition from winter to spring. During the winter, $\tau$ was generally directed out of the fjord $\left(-0.4 \pm 3 \times 10^{-2} \mathrm{~N} \mathrm{~m}^{-2}\right)$ and displayed oscillations with a period longer than 1 day. There were also strong events $\left(>0.2 \mathrm{~N} \mathrm{~m}^{-2}\right)$ during the first half of August 2008 that could be associated with the end of winter storms in the region. This winter pattern drastically changed during the early spring (first week of September 2008) and was maintained throughout the rest of the season. Changes were evident in a marked daily cycle and in switches from down- to up-fjord (average of $1.6 \pm 3 \times 10^{-2} \mathrm{~N} \mathrm{~m}^{-2}$ ), against the upper layer outflow (Fig. 3a).

The sea level was measured at the mouth and near Cochamo (Fig. 1). At both stations, the form factor was 0.12 , which indicates that semi-diurnal tides dominate in the region. In fact, the $\mathrm{M}_{2}$ amplitude was $1.89 \pm 0.06$ at the mouth and $1.91 \pm 0.06 \mathrm{~m}$ near Cochamo. The mouth-to-head phase difference in this harmonic was negative $\left(-2.4^{\circ}\right)$, indicating propagation toward the head with a lag of approximately $5 \mathrm{~min}$. The maximum tidal range during spring tides was approximately $6 \mathrm{~m}$ and less than $1 \mathrm{~m}$ during neap tides (Fig. 3b). 


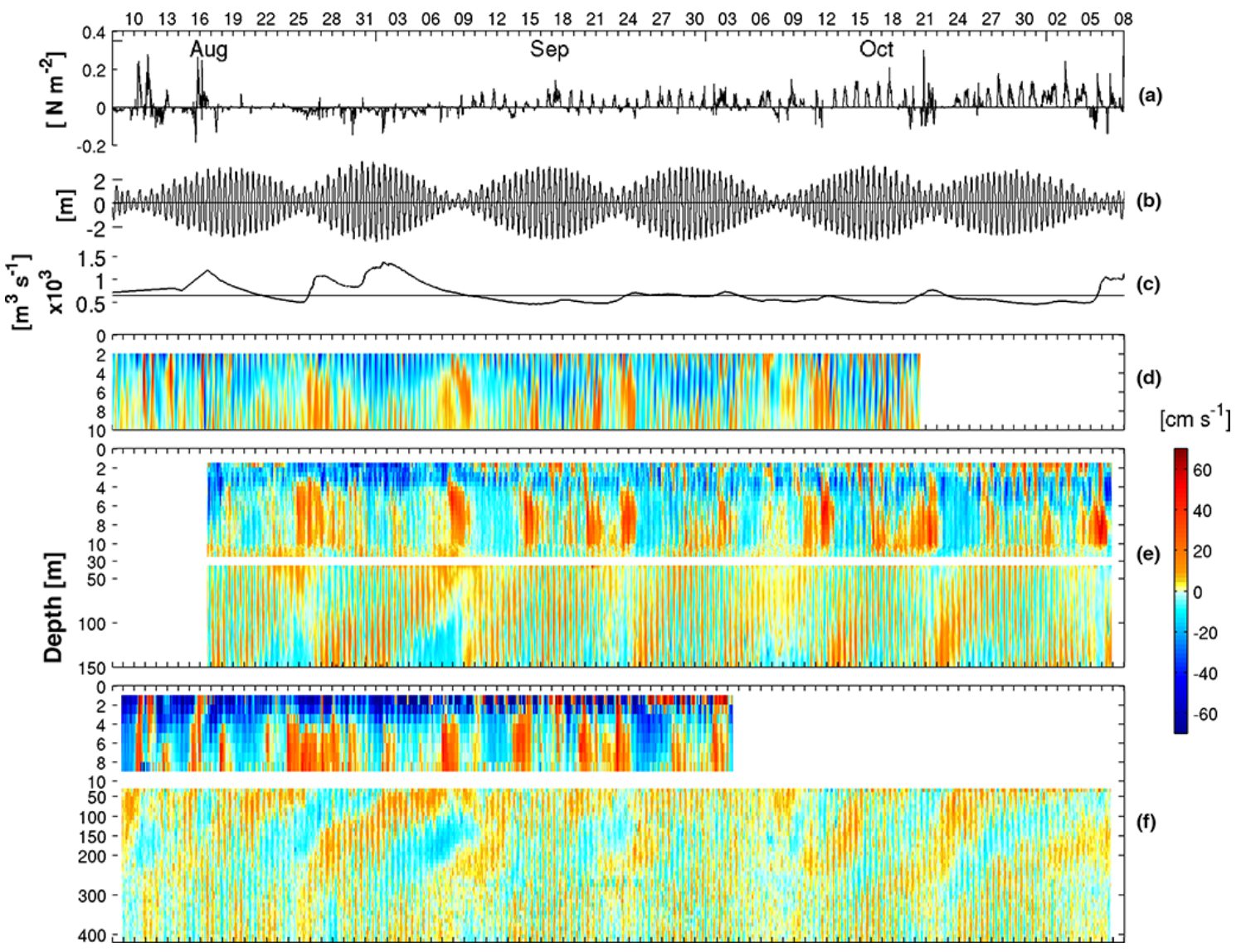

Figure 3. (a) Along-fjord wind stress, positive up to the fjord, (b) sea-level, and (c) Puelo River discharge, where the straight line represents the long-term mean. Contours of along-fjord currents at (d) Cochamo, (e) Puelo, and (f) the mouth; in the filled contours, the blue (red) colors indicate a net outflow (inflow).

Similar ranges have been observed outside the fjord in the Reloncaví sound (Aiken, 2008).

Discharge was greatest (approximately $1413 \mathrm{~m}^{3} \mathrm{~s}^{-1}$ ) at the end of August 2008 (winter) and lower (approximately $459 \mathrm{~m}^{3} \mathrm{~s}^{-1}$ ) at the end of October (spring). In the winter, the historical mean of $650 \mathrm{~m}^{3} \mathrm{~s}^{-1}$ (Niemeyer and Cereceda, 1984; Leon et al., 2013) was exceeded $86 \%$ of the time, whereas during the spring, this exceedance occurred only $18 \%$ of the time. In fact, only a small variability around the mean was observed during the spring (Fig. 3c).

\subsection{Along-fjord currents}

The along-fjord currents were 1 order of magnitude larger than the cross-fjord currents (in this study we focused on the along-fjord component). At the three measurement sites at Cochamo (Fig. 3d), Puelo (Fig. 3e), and the mouth (Fig. 3f), the along-fjord currents displayed certain common features: (1) semi-diurnal oscillations attributed to tidal effect, (2) a two-layered structure with persistent outflow above the pycnocline and an intermittent lower inflow layer beneath, and (3) several low-frequency (period $>1$ day) oscillations present in the time series.

Currents in the upper outflow layer displayed a mean velocity of $66 \mathrm{~cm} \mathrm{~s}^{-1}$ at the mouth and $45 \mathrm{~cm} \mathrm{~s}^{-1}$ at Cochamo, indicating that the outflow increased through the mouth. Additionally, the upper layer was deeper at Cochamo (Fig. 3d) than at the mouth (Fig. 3f), which is consistent with the along-fjord pycnocline depth (Fig. 2). Below the upper layer, a sub-surface layer displayed intermittent inflow (see Fig. 3d, $\mathrm{e}$, and $\mathrm{f})$ with a maximum $\left(>20 \mathrm{~cm} \mathrm{~s}^{-1}\right)$ centered at the $\sim 6 \mathrm{~m}$ depth.

This two-layered pattern was clearly observed in the upper $10-15 \mathrm{~m}$ and is consistent with a gravitational circulation due to the along-fjord pressure gradient. This pressure gradient is also consistent with the observed along-fjord pycnocline tilt (Fig. 2). At depths $>20 \mathrm{~m}$, the along-fjord currents at Puelo and at the mouth exhibited an important influence ( $>40 \%$ of the variability) of a semi-diurnal component of the tide. In addition, in this layer, low-frequency (periods $>7$ days) oscillations suggest a bottom-to-surface propagation that was more intense from the end of August to the beginning of September during a period of high discharge $\left(>650 \mathrm{~m}^{3} \mathrm{~s}^{-1}\right)$. 


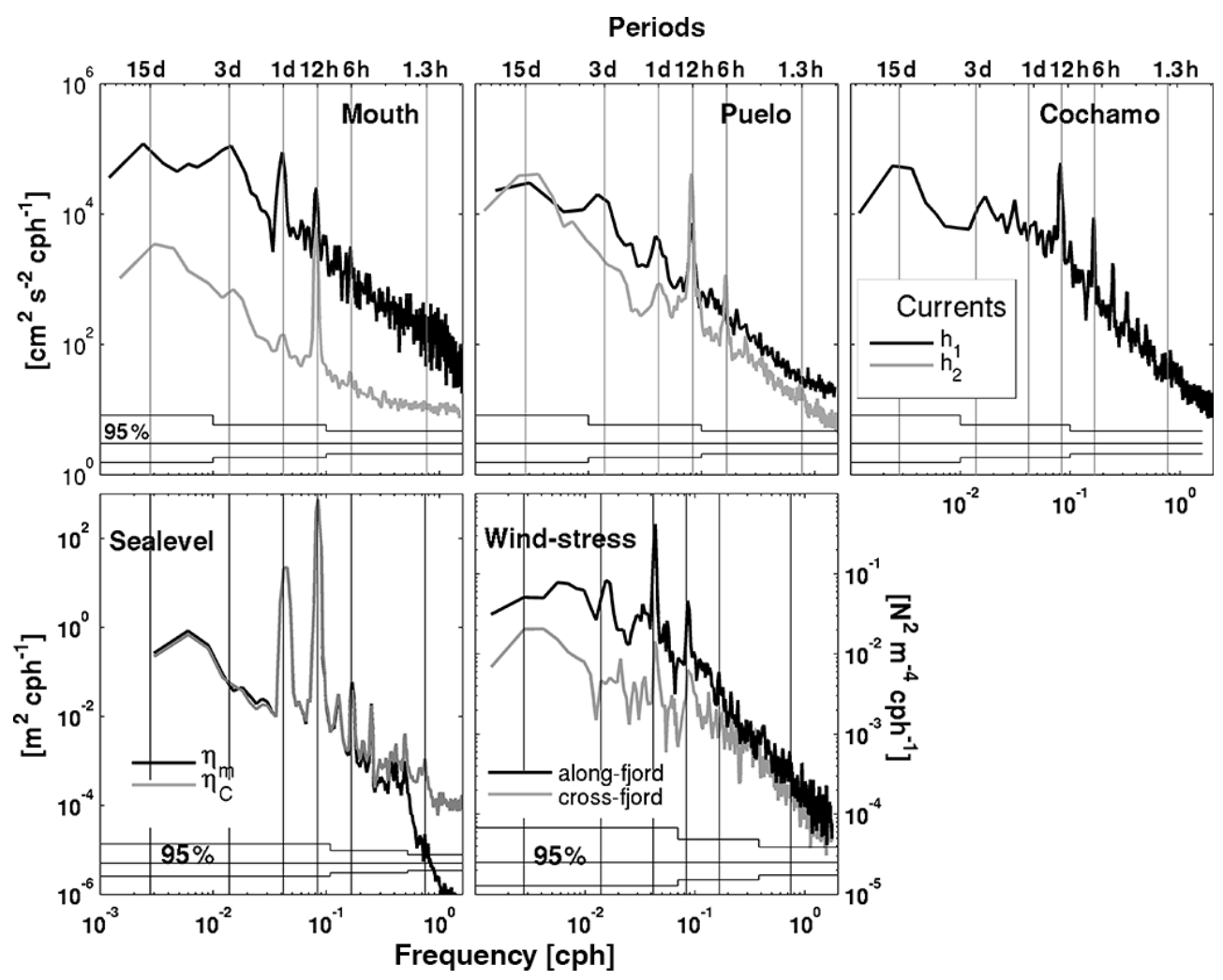

Figure 4. Spectra of along-fjord currents (top) at (a) the mouth, (b) Puelo, and (c) Cochamo. Here the black lines indicate the averaged spectra for the upper layer (depths $\leq h_{1}$ ), whereas the gray lines show spectra for currents at depths $>h_{1}$. (d) Sea-level spectra at the mouth (black line) and at Cochamo (gray). (e) Wind stress spectra for their along-fjord (black) and cross-fjord (gray) components. At the bottom of each panel the $95 \%$ confidence intervals for 48,24 , and 12 degrees of freedom are shown.

This layer on average exhibited a weak outflow $\left(\sim 1 \mathrm{~cm} \mathrm{~s}^{-1}\right)$ at the mouth, which in turn implies a three-layered pattern of the residual flow near the mouth.

\subsection{Spectral characteristics of currents, temperature, sea level, and winds}

To obtain better statistical reliability, the spectra of the alongfjord currents were depth-averaged. The upper layer was defined until the pycnocline depth $\left(z \leq h_{1}\right)$, whereas the deep layer contains $z>h_{1}$ (Fig. 4).

All of the spectra displayed an energetic peak at the semidiurnal frequency $\left(\mathrm{M}_{2}\right)$, and this peak was greater in the deep layer (Fig. 4). In the diurnal band, the spectra at Puelo and at the mouth presented a clear (and highly energetic) peak in the surface layers. This diurnal peak is likely due to the influence of wind stress (see Fig. S1 in the Supplement), which displayed a marked diurnal cycle during the late winter (end of August) and spring (Fig. 3a). An important peak $\left(10^{4} \mathrm{~cm}^{2} \mathrm{~s}^{-2} \mathrm{cph}^{-1}\right)$ was observed only at Cochamo in the $6 \mathrm{~h}$ band $\left(\mathrm{M}_{4}\right)$, suggesting an increase in the importance of non-linear interaction between $\mathrm{M}_{2}$ and the bathymetry in this sub-basin. The spectra in the upper layer displayed an important accumulation of energy in the band centered on the 3-day period. The band was wider (between 2 and 7 days) at the mouth and Puelo and narrower (between 1.5 and 4 days) at Cochamo. At the mouth, the maximum spectral density was in the 3-day band $\left(>10^{5} \mathrm{~cm}^{2} \mathrm{~s}^{-2} \mathrm{cph}^{-1}\right)$ and was 1 order of magnitude greater than the maximum spectral density observed at Cochamo $\left(\sim 10^{4} \mathrm{~cm}^{2} \mathrm{~s}^{-2} \mathrm{cph}^{-1}\right)$. Another important accumulation of energy in the along-fjord currents was centered on the 15-day period. One characteristic of the 15day band is the influence on the entire water column at Puelo and the mouth (Fig. 4).

The sea levels at Cochamo $\left(\eta_{\mathrm{C}}\right)$ and at the mouth $\left(\eta_{\mathrm{m}}\right)$ were similar at frequencies of less than $0.165 \mathrm{cph}$ (periods longer than $6 \mathrm{~h}$ ). The spectra displayed an important accumulation in the synoptic band (10 days). Both locations exhibited the same energy at the diurnal $\left(\mathrm{K}_{1}\right)$ semidiurnal $\left(\mathrm{M}_{2}\right)$ frequencies, although $\mathrm{M}_{2}$ was clearly the dominant harmonic in the fjord. The spectral energy was 1 order of magnitude higher than the diurnal $\left(\mathrm{K}_{1}\right)$ harmonics and 3 orders of magnitude higher than the quarter-diurnal $\left(\mathrm{M}_{4}\right)$ harmonics. The spectra exhibited no accumulation of energy in the 3-day band, although at high frequencies $(>0.5 \mathrm{cph})$, an important accumulation of energy was observed in the $1.3 \mathrm{~h}$ band (between 1.16 and $1.56 \mathrm{~h}$ ) at $\eta_{\mathrm{C}}$ (Fig. 4). 
The wind stress $(\tau)$ indicated that the along-fjord wind stress was significantly higher than the cross-fjord component. The spectra displayed a marked peak (particularly in the along-fjord component) in the diurnal band, which is likely due to the sea-breeze phenomenon. Another interesting feature of the spectrum was the peak in the semi-diurnal frequency, which was observed in both components. At longer periods ( $>1$ day), the along-fjord wind stress displayed an important but not statistically significant peak at 2.8 days, which is highly consistent with the currents (Fig. 4).

\subsection{Seasonality of the internal oscillations}

The density structure on the fjord does not show an upper mixing layer along the seasons; indeed, a continuously stratified upper layer is present along the seasons (Fig. 5). The along-fjord mean of the pycnocline depth $\left(h_{1}\right)$, which was estimated based on a salinity/density gradient, was used to estimate the internal phase velocity $(c)$ and the internal period $\left(T_{\mathrm{N}}\right)$. Seasonally, $h_{1}$ does not change significantly during winter, spring, and summer (between 4.6 and $4.8 \mathrm{~m}$ ), but was shallower during autumn $(\sim 4.1 \mathrm{~m}$; Table 2$)$.

In the case of the RGM approximation, internal phase velocities (c) were highest during spring and summer $\left(>0.83 \mathrm{~m} \mathrm{~s}^{-1}\right)$, whereas in winter and autumn the intensities were $<0.76 \mathrm{~m} \mathrm{~s}^{-1}$; thus, we obtain internal periods between 2.9 and 3.4 days (70 and $82 \mathrm{~h}$; Table 2).

The horizontal velocity structure $\left(\psi_{n}\right)$ profile of the first three internal modes obtained from the CSM showed high consistency along the fjord (in each sub-basin) and through the seasons (Fig. 5). Mode 1 was highly baroclinic, changing sign at nearly 10 (sub-basin I) and $15 \mathrm{~m}$ (sub-basin IV). In the case of modes 2 and 3, relatively high variability along the seasons was observed, especially at sub-basins I and IV above $20 \mathrm{~m}$ in depth. For depths $>30 \mathrm{~m}$ (not shown in Fig. 5), the internal modes do not show significant variability. The modal speeds for the first three modes described above were relatively high during spring and summer $\left(c_{1}\right.$ was $>0.84 \mathrm{~m} \mathrm{~s}^{-1}$ ) and lower during winter and autumn (here $c_{1}$ was $<0.77 \mathrm{~m} \mathrm{~s}^{-1}$ ). These results were highly consistent with the internal speeds obtained by the RGM (Table 2).

Like the internal speeds $(c)$, the natural internal period $\left(T_{\mathrm{N}}\right)$ obtained by the RGM with mode 1 of the CSM was highly consistent. For comparison, we take into account $T_{\mathrm{N}}$ obtained from mode 1 of the CSM, which ranged between 2.9 days (spring) and 3.5 days (winter). The estimations of $T_{\mathrm{N}}$ with RGM showed speeds between 2.9 days (spring) and 3.4 days (winter and autumn), indicating that oscillations between these periods are dominated by mode 1 internal seiche oscillation.

To focus on these internal seiche oscillations, we filtered the along-fjord currents with a 70 to $90 \mathrm{~h}$ cosine-Lanczos band-pass filter. Additionally, mode 1 of the internal seiche was associated with the pycnocline depth, which is restricted to the upper $8 \mathrm{~m}$ (Fig. 2). Therefore, we describe the alongfjord currents in the upper $10 \mathrm{~m}$ (Fig. 6).

The vertical pattern at the three locations shows inflow/outflow intermittence along the whole time series; also most of these along-fjord structures seem to develop an inclination which indicates the baroclinic nature of this pattern. The band-pass along-fjord currents were intense at the mouth $\left(>15 \mathrm{~cm} \mathrm{~s}^{-1}\right)$, but diminish toward the head. Intense perturbation oscillations were observed near the surface between 10 and 20 August 2008 at the mouth and Cochamo; internal intensification (between 4 and $10 \mathrm{~m}$ in depth) of the inflow/outflow pattern was clear at Puelo and Cochamo at the end of September. To decide whether the nature of the along-fjord current pattern was baroclinic or barotropic, we used $\psi_{n}(z)$ to project the band-pass currents (Eqs. 3 and 4), similarly to van der Lee and Umlauf (2011).

The agreement between the 3-day band pass and the projected along-fjord currents at the mouth is shown in Fig. 7. Using only the first three modes, it was possible to explain more than $70 \%$ of the band-pass variability, changes in the outflow/inflow were highly consistent, and the intensifications at the surface were clearly shown by the projected modes. In addition, the vertical structures of the outflow/inflow were well defined by the projections. To make an approximation of the relative importance of the currents' variability, we estimated kinetic energy $\left(K_{\mathrm{E}}=\left(u^{2}+v^{2}\right) / 2\right)$ of (i) the projected modes 1-3, (ii) the 3-day band pass, and (iii) the semi-diurnal $(12 \mathrm{~h})+$ diurnal band pass (1-day) along-fjord currents at the mouth.

The vertically averaged $K_{\mathrm{E}}$ obtained with a 3-day band pass was higher than that generated with the other components (modes 1-3); the maximum was observed in the period 9-18 August (Fig. 7), which is consistent with the windstress intensification shown in Fig. 3a. During that period, the modal $K_{\mathrm{E}}$ was about one-third of the 3-day band-pass kinetic energy; this ratio was higher (i.e., ca. $50 \%$ ) during September. The importance of the tides at the mouth was estimated by summing up the $K_{\mathrm{E}}$ of the diurnal and semi-diurnal currents. In terms of energy, the $K_{\mathrm{E}}$ contribution of tides was similar to the modal currents (Fig. 7).

Along-currents were highly coherent at a 3-day band, which is the period of the first mode of the internal seiche (Table 2). To describe the temporal variability of this high coherence, along the time, we selected $3 \mathrm{~m}$ depth ADCP bins (on the upper layer) from the mouth, Puelo, and Cochamo to make a Morlet cross-wavelet analysis and to estimate the squared coherence (only referred to as coherence hereafter) and phase spectra for the relations mouth-Puelo (MP; Fig. 8b, c) and Puelo-Cochamo (PC; Fig. 8d, e). Both relations showed high coherence in the semi-diurnal and diurnal bands, especially during spring tides.

A low coherence $(<0.6)$ was observed during the downfjord winds (Fig. 8a and b). Similarly, the coherence for the $\mathrm{PC}$ relation was high along the 3-day band, except during the change of the wind direction described above (Fig. 8d). The 


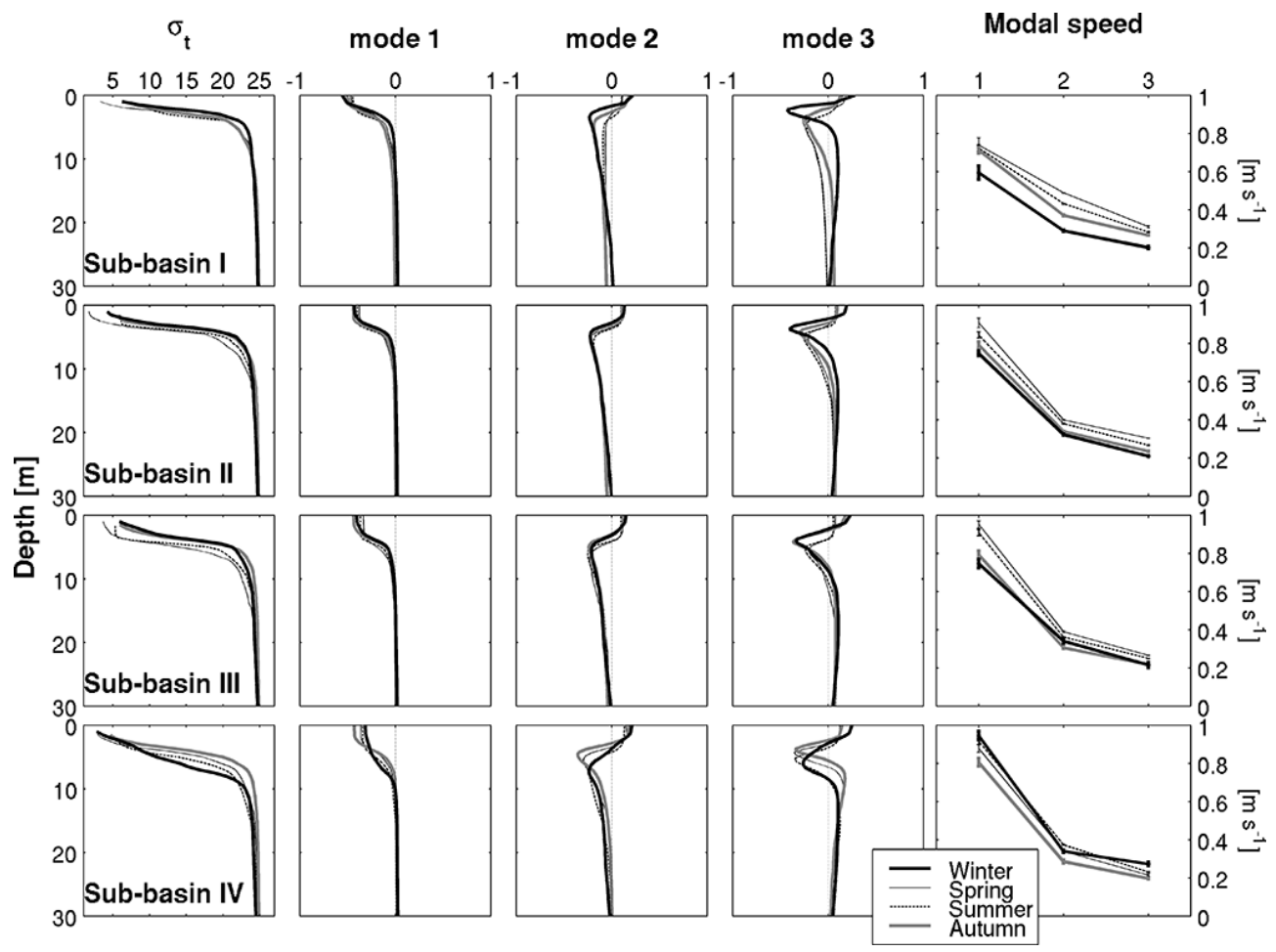

Figure 5. The left panel shows mean density $\left(\sigma_{t}\right)$ within the sub-basins. The panels to the right of these show the first three baroclinic $\psi_{n}(z)$ modes and modal speeds obtained from the CSM analysis (normalized). Note that phase velocity is in $\mathrm{m} \mathrm{s}^{-1}$.

associated phase spectra (only the significant coherence) at the 3-day band was $\sim 0^{\circ}$, indicating that the oscillation is in phase along the fjord (Fig. 8c and e).

At the beginning of the time series, intense fluctuations were observed at Cochamo and at the mouth (Fig. 6). To explore their relationship with the wind forcing, a detailed view of the period between 8 and 31 August 2008 is presented in Fig. 9. During this period, the along-fjord wind stress (not filtered) displayed three different states: (a) strong $\left(>0.2 \mathrm{~N} \mathrm{~m}^{-2}\right)$ up-fjord winds, (b) weak $\left(<0.1 \mathrm{~N} \mathrm{~m}^{-2}\right)$ or nearly calm winds, and (c) moderate $\left(\sim-0.1 \mathrm{~N} \mathrm{~m}^{-2}\right)$ downfjord winds. During (c), the winds displayed an apparent diurnal cycle (e.g., Fig. 3a).

Although density is dominated by salinity, changes in the surface heat exchange may seasonally play a role in the upper column. The rivers in the region are colder in winter, producing a clear thermal inversion (Castillo et al., 2016), while in summer the surface waters reach $18^{\circ} \mathrm{C}$ by the heat gained by solar radiation. But the persistent pycnocline depth along the seasons is consistent, with the freshwater input suggesting that the variability of the density in the upper layer is dominated by the freshwater input instead of the surface heating/cooling variability. We used temperature moorings to emphasize that the internal oscillation reported here had an expression in other properties of the water within the fjord. In addition, the band-pass temperature time series and the along-fjord currents show consistent oscillation patterns
(Fig. 9). During (a), the upper outflows weakened due to the opposing winds at the surface. This change reached depths down to the pycnocline (Fig. 2), causing a disruption and subsequently forcing of the internal oscillations observed in the currents and temperature fields (Fig. 9). Here, intense perturbations were observed that weakened the surface outflow and introduced the colder water of the upper layer to depths $>2 \mathrm{~m}$ at Cochamo and Puelo. During (b), the upper outflow displayed minimum perturbations in both the currents and temperature. In (c), perturbations in the currents and temperature were evident at Cochamo and at the mouth with no major oscillations at Puelo (Fig. 9). In addition, 3-day bandpass vertical velocities $(w)$ were included as arrows on the contours of the along-fjord currents in Fig. 9. The maximum $w$ were $1 \mathrm{~cm} \mathrm{~s}^{-1}$ at the mouth; outflow (inflow) was related to downward (upward) circulation in the entire fjord. This implies that the oscillation observed on the along-fjord currents was also consistent with the vertical velocity patterns.

\section{Discussion}

We used data collected in one of the most extensive studies ever conducted in a Chilean fjord. The data included currents (ADCPs) and temperatures from moored instruments, seasonal CTD information, and times series of winds and sea 


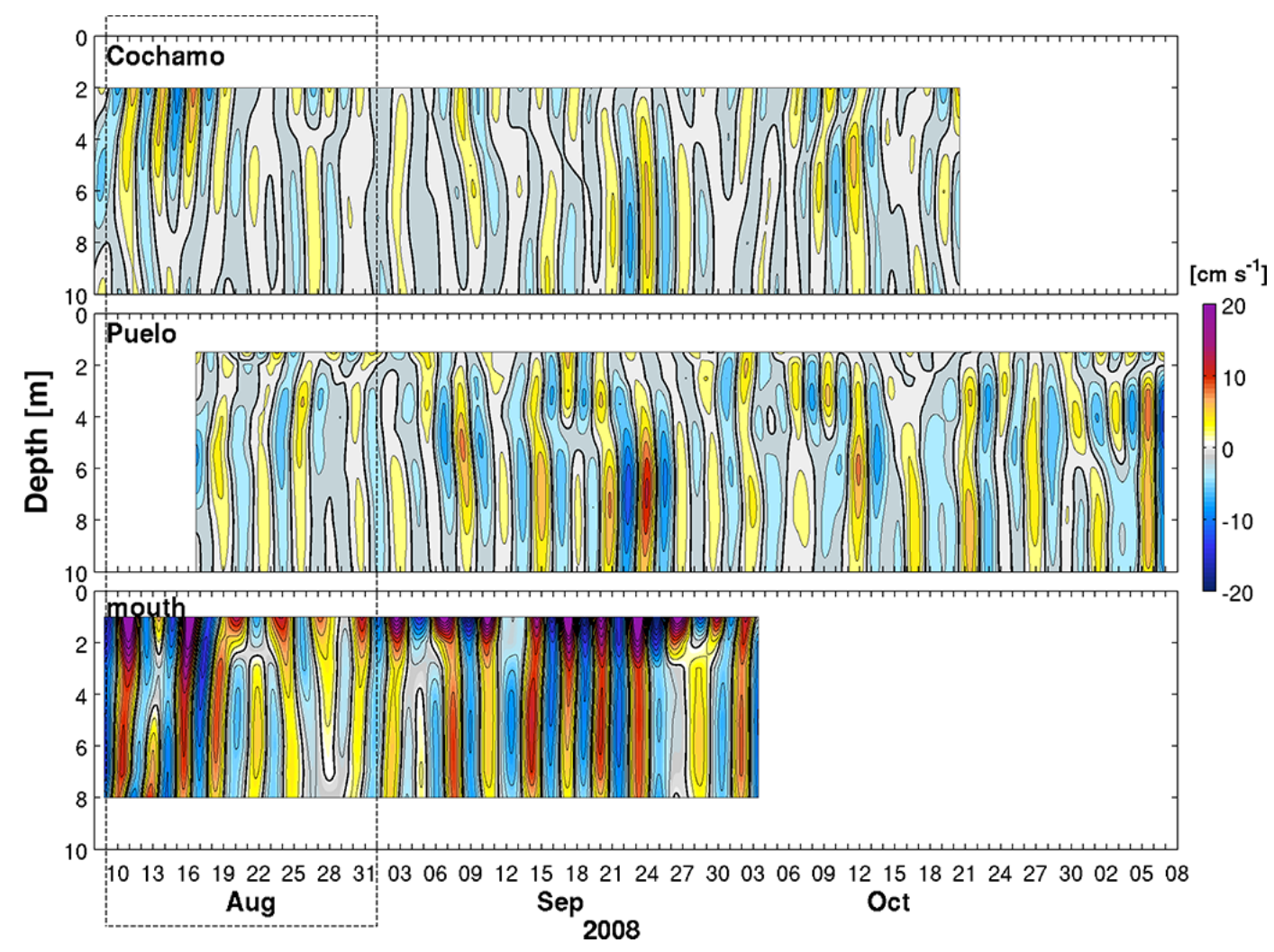

Figure 6. Band-passed along-fjord currents. Contours of band-passed (700-90 h) along-fjord currents. Negative (positive) currents in blue (in red) imply an outflow (inflow). Note the dotted square at the middle of August: it is zooming on Fig. 9.

level to study the dynamics of the internal seiche oscillations in the Reloncaví fjord.

In fjords with shallow sills, such as the Gullmar fjord in Sweden (Arneborg and Liljebladh, 2001a), the Knight Inlet in Canada (Farmer and Freeland, 1983) and the Aysen fjord in Chile (Cáceres et al., 2002), internal tide oscillations may play a major role in the internal mixing (e.g., Stigebrandt, 1976; Farmer and Smith, 1980). In lakes, large internal seiche oscillations significantly contribute to the mixing of the entire basin (Cossu and Wells, 2013), and these oscillations could also be important in fjords where the relative importance of internal tides may be less than the internal seiche oscillations (Arneborg and Liljebladh, 2001b). The semi-diurnal signal in the spectra of the along-fjord currents (Fig. 4) suggests the relative importance of internal tides for the region which is similar to other fjord regions (e.g., Stigebrandt, 1976; Allen and Simpson, 1998; Valle-Levinson et al., 2007). The tidal interaction with the bathymetry is not the only mechanism to produce internal oscillations. Recently, Ross et al. $(2014,2015)$ showed the forcing by glacier lake outburst floods (GLOFs) and by low-frequency changes in barometric pressure. The importance of the internal tides for the southern Patagonian fjords is unknown and future research should be conducted to determine its contribution to the dynamics of currents and mixing.
In this study, we demonstrate the presence (and persistence) of seiches in a Chilean fjord based on the sea-level slope (barotropic seiche), currents, and temperatures (internal seiche). We also studied the main processes forcing the natural oscillation of the pycnocline.

The basic dynamics of a barotropic seiche in a fjord originate from winds tilting the along-fjord surface and piling up water at the head of the fjord. The entire fjord basin begins to oscillate after the cessation of the wind. The maximum amplitude of the seiche is located at the head, whereas a node (zero amplitude) is located at the mouth of the fjord (Dyer, 1997; Rabinovich, 2010). During a baroclinic seiche, winds events perturb the pycnocline to induce oscillations with a period commensurate with the fjord stratification (Djurfeldt, 1987). The horizontal structure of currents associated with the seiche dynamics is related to the standing wave nature of the seiche oscillation where the maximum currents occur in a node (the mouth) and minimum currents are present in an anti-node (the head) in both closed and semi-closed basins (Dyer, 1997; Rabinovich, 2010).

At high frequencies, the tidal spectrum (Fig. 4) displayed a clear accumulation of energy centered at a period of $1.3 \mathrm{~h}$. This frequency is not related to any tidal harmonic interaction (Pawlowicz et al., 2002), and the shape of the spectrum (not a peak) suggests resonance in this frequency band. We 


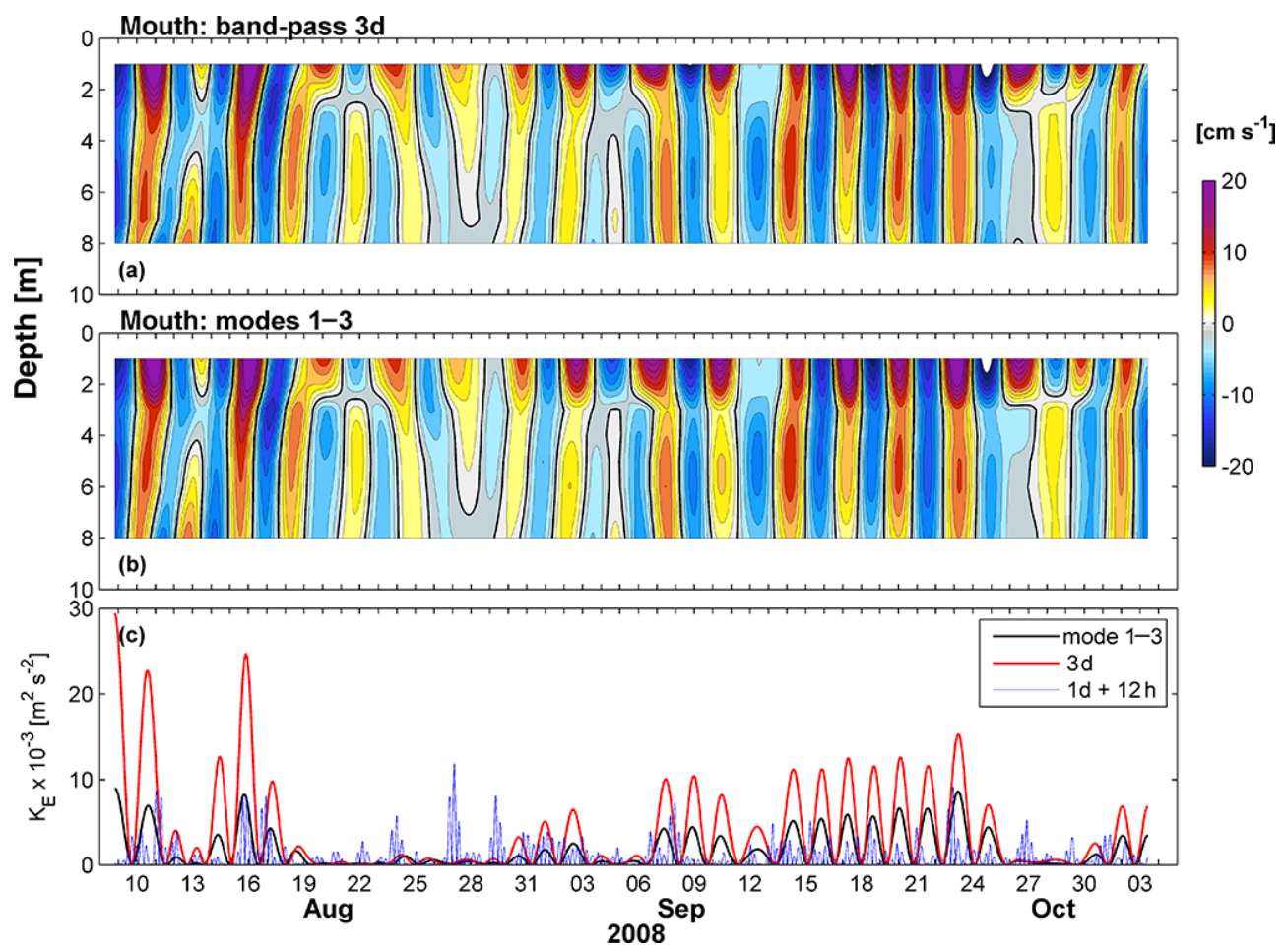

Figure 7. (a) Reconstruction of the along-fjord band-passed currents at the mouth using modes 1-3, (b) band-passed along-fjord currents at the mouth, (c) kinetic energy $\left(K_{\mathrm{E}}\right)$ estimated using reconstructed currents (black), the 3-day band-pass currents (red), and the diurnal and semi-diurnal band-pass currents (blue).

explored the effect of the natural oscillation of the basin in this pattern using the barotropic phase velocity $(c)$ for a shallow water wave $c=(g h)^{1 / 2}$, where $h$ is the mean depth of the fjord. If one assumes a mean fjord depth of $h=250 \mathrm{~m}$ (Table 1), then $c=49.5 \mathrm{~m} \mathrm{~s}^{-1}$ and the natural period $T_{\mathrm{N}}=$ $4 \mathrm{~L} \mathrm{c}^{-1}=1.24 \mathrm{~h}$. This period is lower than the observed period in Fig. $5(1.3 \mathrm{~h})$ because the mean depth takes into account the entire fjord bottom profile (Fig. 1), and thus the effective depth (up to Cochamo) was $233 \mathrm{~m}$, and it is closer to the $226 \mathrm{~m}$ necessary to obtain the observed period in Fig. 5 . Winds in the region are moderate (see Fig. 3), but their intensity is sufficient to tilt the surface slope at Cochamo (Castillo et al., 2012), and thus the surface of the fjord oscillates with the natural period of the basin. Further evidence of this pattern is provided by the clear differences in amplitude of the sea-level spectrum at Cochamo (near the fjord's head) and at the mouth. This association is attributed to the dynamics of seiches in fjords, which tend to produce a node at the mouth and an anti-node at the head (Dyer, 1997). At the node, the sea-level amplitude must be zero, whereas near the head, it must be a maximum. This pattern is highly consistent with the observed spectra at $1.3 \mathrm{~h}$ (Fig. 5). Based on all of these results, we suggest that oscillations close to $1.3 \mathrm{~h}$ will resonate with the natural period along the fjord.

Daily winds were highly coherent with surface along-fjord currents, especially in the brackish water layer (Fig. S1).
During the spring, the daily periodicity of winds was strong (Castillo et al., 2016), with intensities capable of perturbing the pycnocline and inducing the internal seiching process.

The surface slope indicates that the sea level at Cochamo was $0.07 \mathrm{~m}$ higher than at the mouth, and this value can be taken as the amplitude of the surface seiche. According to the RGM, the pycnocline deviation $\left(\eta_{1}\right)$ is related to the surface elevation $\left(\eta_{0}\right)$ in the form $\eta_{1}=-(\rho / \Delta \rho) \eta_{0}$, which implies that for a mean surface perturbation of $0.07 \mathrm{~m}$ and a typical $\Delta \rho$ of $15 \mathrm{~kg} \mathrm{~m}^{-3}$, we obtain a mean $\eta_{1}$ of $-4.8 \mathrm{~m}$. This finding indicates that the water piles up at the head of the fjord, likely due to the predominant fjord winds in the region (Fig. 3a), and produces a pycnocline deepening of about $5 \mathrm{~m}$ (Fig. 2).

At low frequencies (periods $>1$ day), the along-fjord current spectra displayed a marked peak in energy centered at 3 days. To explore the origin of this variability, we analyzed the density profiles along the fjord (Fig. 2) and applied two methods, the RGM and the CSM. The internal phase velocities $(c)$ obtained from both methods were similar, and ranged between 0.73 and $0.87 \mathrm{~m} \mathrm{~s}^{-1}$ (taking into account mode 1 of the CSM for comparison). The high $c$ value was obtained during the spring (November 2008), when the upper layer presented the lowest densities of the seasons, likely due to high discharge $\left(>1000 \mathrm{~m}^{3} \mathrm{~s}^{-1}\right)$. Remarkably, the stratification is linked to the freshwater input despite no major ob- 

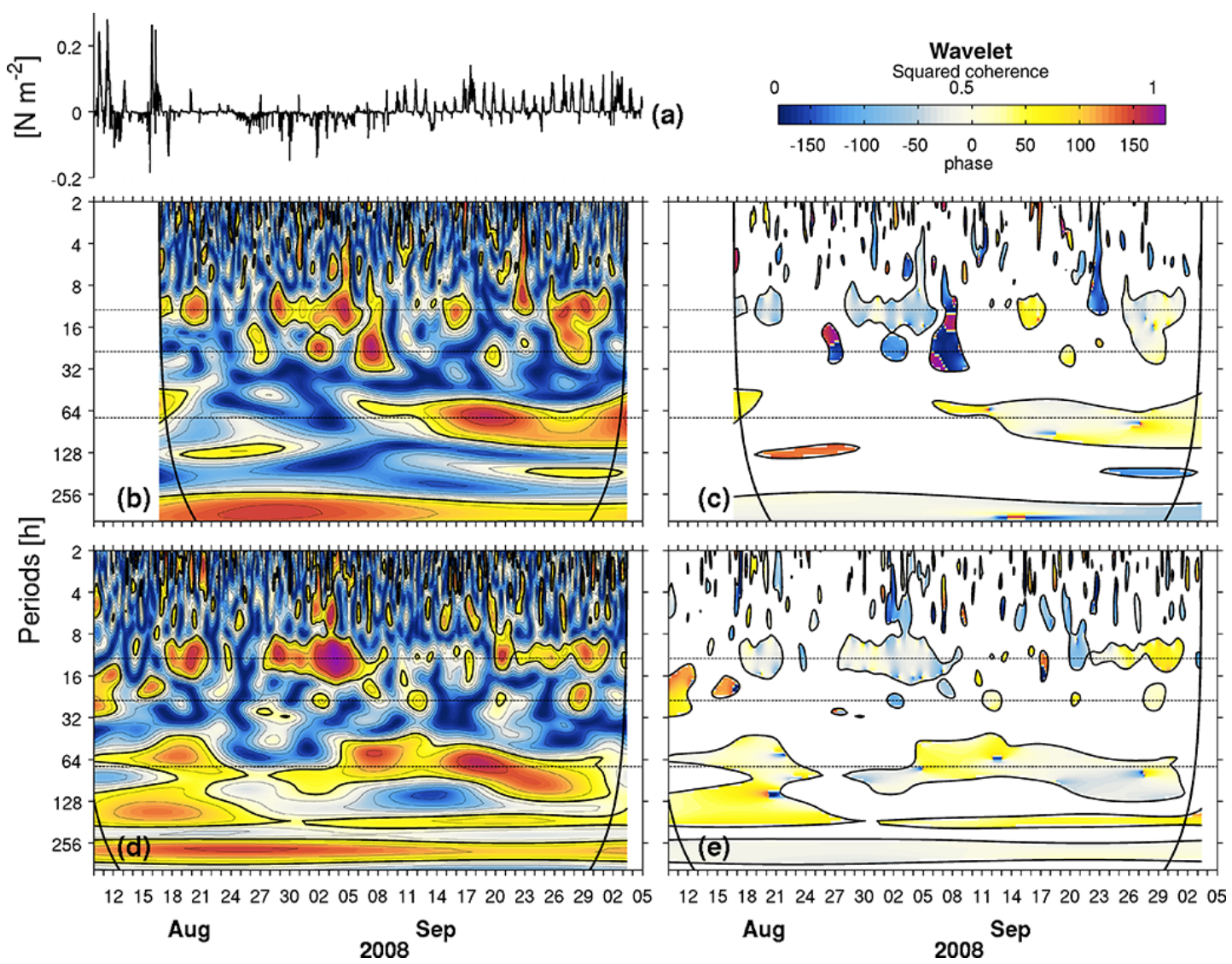

Figure 8. Coherence and phase wavelet spectra. (a) Time series of along-fjord wind stress, and (b, c, d, e) coherence and phase wavelet spectra, for the relations mouth-Puelo $(\mathbf{b}, \mathbf{c})$ and Puelo-Cochamo $(\mathbf{d}, \mathbf{e})$. In the contours, the thick black line indicates squared coherence $\geq 0.6$; only the associated phases were present on the phase wavelet. The thick black curve is the influence cone for the wavelet estimations.

served changes in $c$ (Fig. 6e-h). The high consistency between the CSM (mode 1) modal speeds and the phase speed obtained by the RGM suggest that rotation does not play a significant role in the along-fjord dynamics of these oscillations (van der Lee and Umlauf, 2011). But cross-fjord, the dynamics has been nearly geostrophic, especially at the fjord's mouth (Castillo et al., 2012).

For longer periods ( $>10$ days), there is evidence of baroclinic oscillations clearly observed in the along-fjord time series (Fig. 3) and in the averaged spectra (Fig. 4). Recently, Ross et al. (2015) described a similar periodicity in currents of a southern Patagonian fjord of Chile associated with baroclinic annular variability, a regional feature in the air pressure in the region. This mechanism of generation for the 10-day oscillations in the Reloncaví fjord needs to be verified in future studies.

The internal $T_{\mathrm{N}}$ of the entire fjord displayed periods between 2.9 and 3.5 days. These results suggest that the accumulation of energy observed in the along-fjord currents is due to the first mode of an internal seiche oscillation in the fjord. This result could be explained by the presence of a node at the mouth, where the sea-level amplitude is minimum
(Fig. 5) but the currents are maxima (Figs. 3 and 6). This difference was also observed in the projected currents $\left(u_{\mathrm{pj}}, v_{\mathrm{pj}}\right)$, supporting the idea of the presence stationary wave along the fjord. Additionally, the currents were highly coherent and in phase (Fig. 8), as we expected from a basin-scale wave-like seiche. As a way to estimate the contribution of the internal seiche to the internal mixing the $K_{\mathrm{E}}$ was enhanced during the fjord winds (Figs. 3 and 7), which were periods when the internal seiche band (3 days) was highly coherent along the fjord (Fig. 8).

The winds exhibited high coherence with the along-fjord currents until the pycnocline depths, at frequencies centered at 1 and 3 days (see Fig. S1). To study the extent to which the wind stress perturbs the pycnocline, we used the Wedderburn number, which is given by the equation $W=\left(h_{1} / L\right) R i$ (Thompson and Imberger, 1980; Monismith, 1986), where $R i=g^{\prime}\left(h_{1} / u_{*}^{2}\right)$ represents the bulk Richardson number, an index of the stability of the upper layer $\left(h_{1}\right)$. The frictional velocity $\left(u_{*}\right)$ is obtained from the surface wind stress using the equation $u_{*}^{2}=\tau / \rho_{0}$, which results in the equation

$$
W=\frac{h_{1}^{2} \Delta \rho g}{L \tau} .
$$




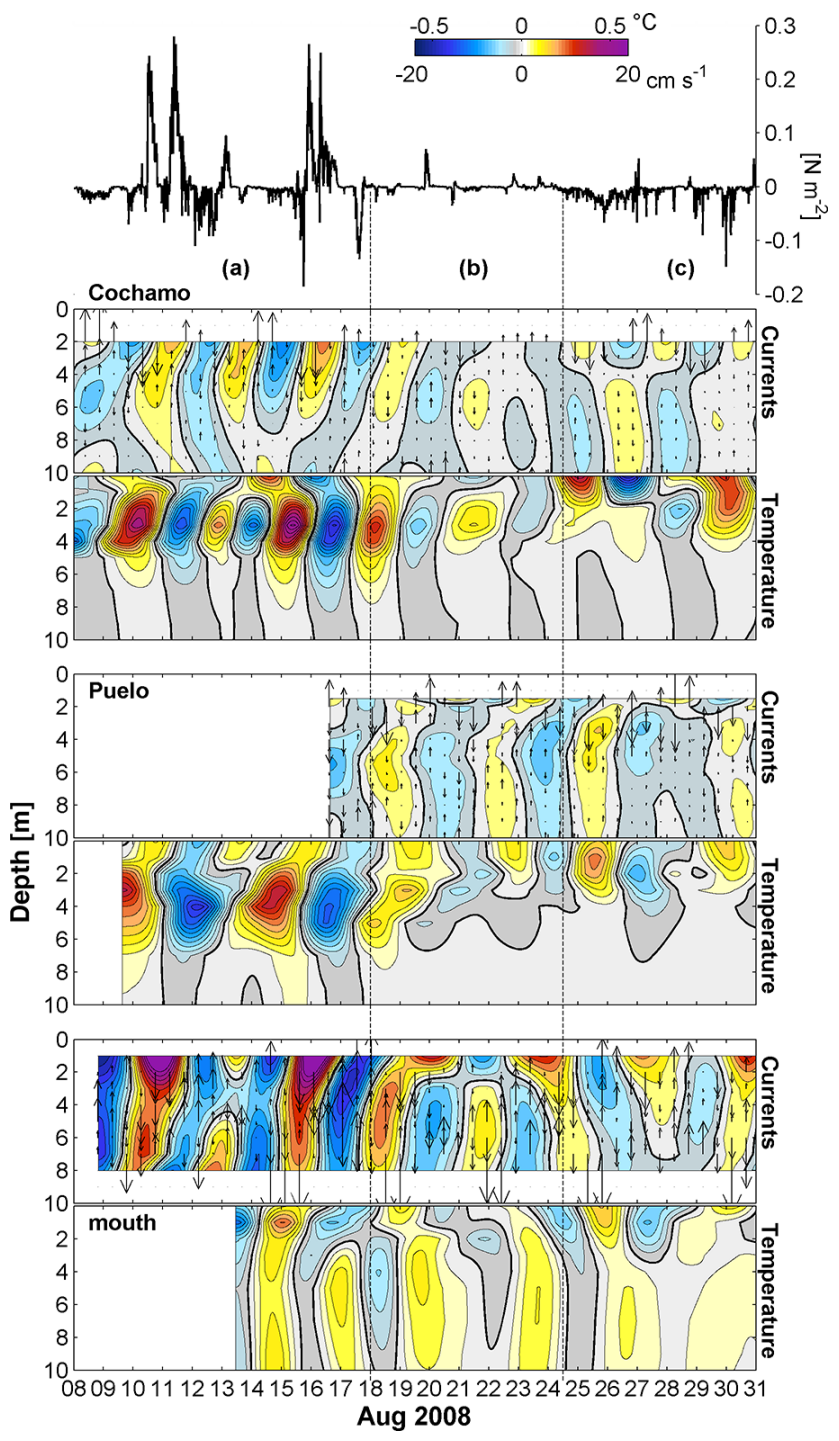

Figure 9. Time series of along-fjord wind stress $(\tau)$ and contours of along-fjord currents and temperatures at Cochamo, Puelo, and the mouth. There are three states of wind stress based on the Wedderburn number $(W)$, with (a) strong $W<1$, (b) weak $W>1$, and (c) moderate $W \sim 1$ winds. Note that contours of the currents and temperature for a given location are plotted together. The arrows represent the 3-day band-pass vertical velocities where the maximum was $1 \mathrm{~cm} \mathrm{~s}^{-1}$

According to Thompson and Imberger (1980), this value indicates the effect of the wind stress on local upwelling in a stratified fluid (i.e., perturbing the pycnocline). Under weak $\tau$ conditions ( $W \gg 1$ ), the wind energy is insufficient to tilt the interface. Under strong $\tau$ conditions ( $W \ll 1$ ), however, upwelling conditions dominate, there by tilting the interface, which produces conditions favorable to forcing of the internal seiche. The critical conditions $(W \sim 1)$ indicate the beginning of upwelling (Thompson and Imberger, 1980; Stevens and Imberger, 1996), although the ideal transition

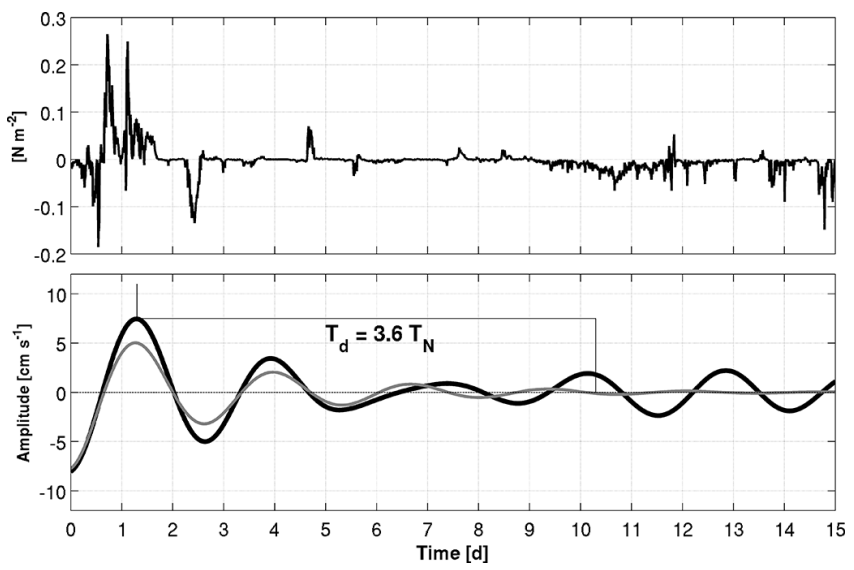

Figure 10. Damping signal in currents during a period of weak winds $(W>1)$ at Cochamo (16 to 24 August 2008). The band-pass currents at $3 \mathrm{~m}$ depth (black line) were compared with a damping oscillatory curve $x(t)=A e^{(-k t)} \cos (\omega t+\phi)$ (gray line). The damping time $\left(T_{\mathrm{d}}\right)$ was 3.6 times longer than the fundamental internal period $\left(T_{\mathrm{N}}\right)$.

point occurs at $W=0.5$ (Monismith, 1986). All of these conditions were observed during the period of August 2008, as is shown in Fig. 9. During strong $\tau\left(\sim 0.3 \mathrm{~N} \mathrm{~m}^{-2}\right)$ conditions, $W=0.27$ produced intense perturbation of the pycnocline (Fig. 9a). In contrast, during weak $\tau\left(\sim 0.01 \mathrm{~N} \mathrm{~m}^{-2}\right)$ conditions, a value of $W=8$ indicates that the wind was too weak to perturb the pycnocline, favoring a seiche damping process (Fig. 9b). Transition conditions occurred when $\tau_{d} \sim 0.1 \mathrm{~N} \mathrm{~m}^{-2}$ and $W=0.8$, indicating that the winds were strong enough to perturb the pycnocline and stop the damping process (Fig. 9c).

\subsection{Internal seiche damping}

The wind stress changed from a state where $\tau$ was strong enough to actively disturb the pycnocline $(W<1)$ to a period of nearly calm winds $(W>1)$ between 16 and $24 \mathrm{Au}-$ gust 2008 (Fig. 9). During this period, both the along-fjord currents and temperatures tended to decay, which is clearly evident in the isolines of these properties at the three sites (Fig. 9).

To study the damping process in detail, we selected the time series of the along-fjord currents at a depth of $3 \mathrm{~m}$ at Cochamo during the above period in August to span the period of forcing, damping, and re-enforcing of the internal oscillation.

Typically, any real oscillations undergo damping, which is given by the equation

$x(t)=A e^{(-k t)} \cos (\omega t+\phi)$

where $t$ is time and $A$ is the initial amplitude, $k$ is the damping coefficient which has units of $\mathrm{s}^{-1}, \omega=2 \pi / T_{\mathrm{N}}$, and $\phi$ is the phase. In the case studied here, $\phi=0, A=8 \mathrm{~cm} \mathrm{~s}^{-1}$, and 
$T_{\mathrm{N}}=2.5$ days, which was the internal period at Cochamo (Fig. 4). The best fit occurred when $k=1 / 3$ (Fig. 10).

The time for the initial amplitude $A$ to decay to $A \sim 0$ is the damping time $\left(T_{\mathrm{d}}\right)$. There was a good fit (Fig. 10) between the observed current and the curve adjusted with the damping effect. Here, $T_{\mathrm{d}}=9.1$ days, which is more than 3 times longer than the natural oscillation $\left(T_{\mathrm{N}}\right)$; more precisely, $T_{\mathrm{d}}=3.6 T_{\mathrm{N}}$ at this site. The observed internal oscillations of the currents were not completely damped because the winds increased from nearly calm $(W>1)$ to moderate conditions, which disturbed the pycnocline $(W \sim 1)$ and induced the intense oscillations during the spring (Fig. 6). In the spring, the winds displayed a marked diurnal cycle that remained during the spring and summer (Castillo et al., 2012). This finding suggests that the internal seiche (mode 1) process is active without damping because it is forced daily (Fig. 3). Our findings indicated that the internal seiche process is an active contributor to the mixing in the Reloncaví fjord; the magnitude of this contribution might be similar to the tidal forcing. The maximum amplitude of the tidal currents in the Reloncaví fjord is $10 \mathrm{~cm} \mathrm{~s}^{-1}$ (Valle-Levinson et al., 2007; Castillo et al., 2012); using $K_{\mathrm{E}}$ to estimate the maximum contribution of the tide obtains $5 \times 10^{-3} \mathrm{~m}^{2} \mathrm{~s}^{-2}$, which is similar to the observed $K_{\mathrm{E}}$ at the mouth (Fig. 7). One example of the dissipation of the energy through this process was observed prior to 19 August 2008 (Fig. 10): then the maximum currents were $0.7 \mathrm{~m} \mathrm{~s}^{-1}$ and, through Eq. (7), we obtain $K_{\mathrm{E}}=7 \times 10^{-3} \mathrm{~m}^{2} \mathrm{~s}^{-2}$, meaning that a great part of this energy might be dissipated within the Reloncaví fjord in 9 days.

\section{Conclusions}

The along-fjord seasonal density structure of the Reloncaví fjord showed small changes in the stratification. The upper layer shows a persistent stratification from the surface to the pycnocline base, the latter of which has a mean depth of $2 \mathrm{~m}$ near the mouth and $6 \mathrm{~m}$ near the head of the fjord.

The along-fjord sea-level signal showed a $1.3 \mathrm{~h}$ energetic peak not related to any tidal harmonics; additionally, at this period the sea-level amplitude at the mouth was significantly higher than the sea level at the head of the fjord. This pattern was consistent with the presence of a barotropic seiche in the Reloncaví fjord.

Local wind stress was able to perturb the along-fjord pycnocline and produce internal seiche oscillations. The period centered on 3 days was consistent with the first baroclinic oscillation mode. This mode explained $44 \%$ of the variability of the 3-day band. The oscillation was highly coherent along the fjord and with a phase close to $0^{\circ}$, consistent with a standing wave, like an internal seiche, within the Reloncaví fjord.

The internal seiche could be a strong contributor to the internal mixing within the fjord; in fact, the kinetic energy
$\left(K_{\mathrm{E}}\right)$ associated with the internal seiche was similar to the maximum contribution of the tides in the along-fjord currents. During winter, the internal oscillations were present a relatively long period of time with nearly calm winds, which permitted the estimation of the damping time of the internal seiche to be 9 days; otherwise, during the spring daily winds continuously forced the pycnocline.

Future studies should focus on evaluating more precisely the available energy for the mixing process within the fjord and their effects on other water properties such as the salinity, oxygen, or nutrients.

\section{Data availability}

The installation of the moorings for measuring the current, temperature, and sea level in the region was approved by the Chilean Navy through permit DS711. No specific permits were required to install the meteorological station because the location is a publicly controlled site. This study also did not involve any endangerment to species in the region. The authors indicated that all data are available to download from a COPAS-SUR Austral (2012) website (http://www.reloncavi.udec.cl/). The discharge data from the rivers of Chile are available from the Dirección General del Aguas de Chile website (http://dgasatel.mop.cl/). Also, all data sets can be requested from the corresponding author (Manuel I. Castillo).

\section{The Supplement related to this article is available online at doi:10.5194/os-13-145-2017-supplement.}

Competing interests. The authors declare that they have no conflict of interest.

Acknowledgements. The authors thank the students (from Chile and Sweden) and technicians of the Physical Oceanography group of the Universidad de Concepción who collaborated in performing the field measurements. This study was funded by the COPAS-Sur Austral CONICYT PIA PFB31 and Centro de Investigación en Ecosistemas de la Patagonia by FIP2007-21. Manuel I. Castillo was supported by CONICYT-PAI no. 791220005 and by FONDECYT no. 11160500 . Finally, we want to thank the three anonymous reviewers and the editor Mario Hoppema for their comments which helped to improve the present paper.

Edited by: M. Hoppema

Reviewed by: three anonymous referees 


\section{References}

Aiken, C. M.: Barotropic tides of the Chilean Inland Sea and their sensitivity to basin geometry, J. Geophys. Res., 113, C08024, doi:10.1029/2007JC004593, 2008.

Allen, G. L. and Simpson, J. H: Reflection of the internal tide in Upper Loch Linnhe, a Scottish fjord, Estuar. Coast. Shelf Sci., 46, 683-701, 1998.

Arneborg, L. and Liljebladh, B.: The internal seiches in Gullmar fjord part I - dynamics, J. Phys. Oceanogr., 31, 2549-2566, 2001a.

Arneborg, L. and Liljebladh, B.: The internal seiches in Gullmar fjord part II - contribution to basin water mixing, J. Phys. Oceanogr., 31, 2567-2574, 2001b.

Cáceres, M., Valle-Levinson, A., Sepúlveda, H., and Holderied, K.: Transverse variability of flow and density in a Chilean fjord, Cont. Shelf Res., 22, 1683-1698, 2002.

Castillo, M. I., Pizarro, O., Cifuentes, U., Ramirez, N., and Djurfeldt, L.: Subtidal dynamics in a deep fjord of southern Chile, Cont. Shelf Res., 49, 73-89, 2012.

Castillo, M. I., Cifuentes, U., Pizarro, O., Djurfeldt, L., and Caceres, M.: Seasonal hydrography and surface outflow in a fjord with a deep sill: the Reloncaví fjord, Chile, Ocean Sci., 12, 533-544, doi:10.5194/os-12-533-2016, 2016.

COPAS-Sur Austral: Oceanografía del fiordo Reloncaví, Universidad de Concepción, available at: http://www.reloncavi.udec.cl/ (last access: 6 June 2016), 2012.

Cossu, R. and Wells, M. G.: The Interaction of Large Amplitude Internal Seiches with a Shallow Sloping Lakebed: Observations of Benthic Turbulence in Lake Simcoe, Ontario, Canada, PLOS One, 8, e57444, doi:10.1371/journal.pone.0057444, 2013.

Dirección General de Aguas: Datos hidrológicos en tiempo real, Chile, available at: http://dgasatel.mop.cl/, last access: 1 July 2016.

Djurfeldt, L.: On the response of the Fjord Gullmaren under ice cover, J. Geophys. Res., 92, 5157-5167, doi:10.1029/JC092iC05p05157, 1987.

Dyer, K. R.: Estuaries: A Physical Introduction, John Wiley and Sons Inc, UK, 140 pp., 1997.

Emery, W. J. and Thomson, R. E.: Data Analysis Methods in Physical Oceanography, Elsevier, New York, USA, 634 pp., 1998.

Farmer, D. M. and Freeland, H. J.: The physical oceanography of Fjords, Prog. Oceanogr., 12, 147-194, doi:10.1016/00796611(83)90004-6, 1983.

Farmer, D. M. and Smith, J.: Tidal interaction of stratified flow with a sill in Knight Inlet, Deep-Sea Res. Pt. I, 27, 239-254, doi:10.1016/0198-0149(80)90015-1, 1980.

Gill, A.: Atmosphere-Ocean Dynamics, Academics Press, USA, 662 pp., 1982.

Goudsmit, G.-H., Burchard, H., Peeters, F., and Wüest, A.: Application of $\mathrm{k}-\epsilon$ turbulence models to enclosed basins: The role of internal seiches, J. Geophys. Res., 107, 3230, doi:10.1029/2001JC000954, 2002.

Grinsted, A., Moore, J. C., and Jevrejeva, S.: Application of the cross wavelet transform and wavelet coherence to geophysical time series, Nonlin. Processes Geophys., 11, 561-566, doi:10.5194/npg-11-561-2004, 2004.

Inall, M. E. and. Rippeth, T. P.: Dissipation of Tidal Energy and Associated Mixing in a Wide Fjord, Environ. Fluid Mech., 2, 219-240, doi:10.1023/A:1019846829875, 2002.
Iriarte, J. L., Pantoja, S., and Daneri, G.: Oceanographic Processes in Chilean Fjords of Patagonia: from small to large-scale studies, Prog. Oceanogr., 129, 1-7, doi:10.1016/j.pocean.2014.10.004, 2014.

Large, W. G. and Pond, S.: Open-ocean momentum flux measurements in moderate to strong winds, J. Phys. Oceanogr., 11, 324336, 1981.

Lemmin, U.: The structure and dynamics of internal waves in Baldeggersee, Limnol. Oceanogr., 32, 43-61, doi:10.4319/lo.1987.32.1.0043, 1987.

León-Muñoz, J., Marcé, R., and Iriarte, J. L.: Influence of hydrological regime of an Andean river on salinity, temperature and oxygen in a Patagonia fjord, Chile, New Zeal. J. Mar. Fresh, 47, 515-528, doi:10.1080/00288330.2013.802700, 2013.

Letelier, J., Soto-Mardones, L., Salinas, S., Osuna, P., López, D., Sepúlveda, H. H., Pinilla, E., and Rodrigo, C.: Variabilidad del viento, oleaje y corrientes en la región norte de los fiordos Patagónicos de Chile, Revista de Biologia Marina y Oceanografía, 46, 363-377, 2011.

Mans, C., Bramato, S., Baquerizo, A., and Losada, M.: Surface Seiche Formation on a Shallow Reservoir in Complex Terrain, J. Hydraul. Eng.-Asce, 137, 517-529, 2011.

Maas, L. R. M. and Lam, F.-P. A.: Geometric focusing of internal waves, J. Fluid Mech., 300, 1-41, doi:10.1017/S0022112095003582, 1995.

Monismith, S.: An experimental study of the upwelling response of stratified reservoirs to surface shear stress, J. Fluid Mech., 171, 407-439, doi:10.1017/S0022112086001507, 1986.

Montero, P., Daneri, G., Gonzalez, H., Iriarte, J. L., Tapia, F. J., Lizarraga, L., Sanchez, N., and Pizarro, O.: Seasonal variability of primary production in a fjord ecosystem of the Chilean Patagonia: Implications for the transfer of carbon within pelagic food webs, Cont. Shelf Res., 31, 202-215, doi:10.1016/j.csr.2010.09.003, 2011.

Mortimer, C. H.: Water movements in lakes during summer stratification; evidence from distribution of temperature in Windermere, Philos. T. R. Soc. London, 236, 355-404, doi:10.1098/rstb.1952.0005, 1952.

Münnich, M., Wuest, A., and Imboden, D. M.: Observations of the 2nd Vertical-Mode of the Internal Seiche in an Alpine Lake, Limnol. Oceanogr., 37, 1705-1719, doi:10.4319/lo.1992.37.8.1705, 1992.

Niemeyer, H. and Cereceda, P.: Hidrografía, Geografía de Chile, Tomo VIII, Instituto Geográfico Militar, Chile, 320 pp., 1984.

Palma, S. and Silva, N.: Distribution of siphonophores, chaetognaths, euphausiids and oceanographic conditions in the fjords and channels of southern Chile, Deep-Sea Res. Pt. II, 51, 513553, doi:10.1016/j.dsr2.2004.05.001, 2004.

Pantoja, S., Iriarte, J. L., and Daneri, G.: Oceanography of the Chilean Patagonia, Cont. Shelf Res., 31, 149-153, doi:10.1016/j.csr.2010.10.013, 2011.

Parsmar, R. and Stigebrandt, A.: Observed damping of barotropic seiches through baroclinic wave drag in the Gullmar Fjord, J. Phys. Oceanogr., 27, 849-857, 1997.

Pawlowicz, R., Beardsley, B., Lentz, S.: Classical tidal harmonic analysis including error estimates in MATLAB using T-TIDE, Comput. Geosci., 28, 929-937, 2002.

Pickard, G. L.: Some Physical Oceanographic Features of Inlets of Chile, J. Fish. Res. Board Can., 28, 1077-1106, 1971. 
Rabinovich, A.: Seiches and Harbor Oscillations, in: Handbook of Coastal and Ocean Engineering, edited by: Kim, Y., World Scientific Publishing Co, US, 193-236, 2010.

Ross, L., Pérez-Santos, I., Valle-Levinson, A., and Schneider, W.: Semidiurnal internal tides in a Patagonian fjord, Prog. Oceanogr., 129, 19-34, doi:10.1016/j.pocean.2014.03.006, 2014.

Ross, L., Valle-Levinson, A., Pérez-Santos, I., Tapia, F. J., and Schneider, W.: Baroclinic annular variability of internal motions in a Patagonian fjord, J. Geophys. Res., 120, 5668-5685, doi:10.1002/2014JC010669, 2015.

Schneider, W., Pérez-Santos, I., Ross, L., Bravo, L., Seguel, R., and Hernández, F.: On the hydrography of Puyuhuapi Channel, Chilean Patagonia, Prog. Oceanogr., 129, 8-18, doi:10.1016/j.pocean.2014.03.007, 2014.

Simpson, J. H., Wiles, P. J., and Lincoln, B. J.: Internal seiche modes and bottom boundary-layer dissipation in a temperate lake from acoustic measurements, Limnol. Oceanogr., 56, 18931906, 2011.

Stevens, C. and Imberger, J.: The initial response of a stratified lake to a surface shear stress, J. Fluid Mech., 312, 39-66, doi:10.1017/S0022112096001917, 1996.

Stigebrandt, A.: Vertical diffusion driven by internal waves in a sill Fjord, J. Phys. Oceanogr., 6, 486-495, 1976.

Stigebrandt, A.: Some aspects of tidal interaction with fjord constrictions, Estuar. Coast. Mar. Sci., 11, 151-166, doi:10.1016/S0302-3524(80)80038-7, 1980.

Stigebrandt, A. and Aure, J.: Vertical Mixing in Basin Waters of Fjords, J. Phys. Oceanogr., 19, 917-926, 1989.

Svendsen, H.: Exchange processes above sill level between fjords and coastal water, in: Fjord Oceanography, edited by: Freeland, H., Farmer, D., and Levings, C., Plenum Press, USA, 355-361, 1980.
Thompson, R. O. R. Y. and Imberger, J.: Response of a numerical model of a stratified lake to a wind stress, in Proceedings of the 2nd International Symposium on Stratified Flows, Trondheim, Norway, 24-27 June 1980, 562-570, 1980.

Thorpe, S.: Near-resonant forcing in a shallow two-layer fluid: a model for the internal surge in Loch New?, J. Fluid Mech., 63, 509-527, doi:10.1017/S0022112074001753, 1974.

Torrence, C. and Compo, G. P.: A practical guide to wavelet analysis, B. Am. Meteorol. Soc., 79, 61-78, 1998.

Valle-Levinson, A., Sarkar, N., Sanay, R., Soto, D., and León, J.: Spatial structure of hydrography and flow in a chilean fjord, Estuario Reloncaví, Estuar. Coast., 30, 113-126, doi:10.1007/BF02782972, 2007.

van der Lee, E. M. and Umlauf, L.: Internal wave mixing in the Baltic Sea: Near-inertial waves in the absence of tides, J. Geophys. Res-Oceans, 116, C10016, doi:10.1029/2011jc007072, 2011.

Watson, E. R.: Movements of the waters of Loch Ness, as indicated by temperature observations, Geogr. J., 24, 430-437, doi:10.2307/1775951, 1904.

Weddernburn, E. M.: An experimental investigation of the temperature changes occurring in fresh-water lochs, P. Roy. Soc. Edinb., 28, 2-20, doi:10.1017/S0370164600011524, 1907.

Weddernburn, E. M. and Young, A.: Temperature observations in Loch Earn, Part II, Trans. R. Sot. Edinb., 50, 741-767, doi:10.1017/S0080456800017026, 1915.

Wiegand, R. C. and Chamberlain, V.: Internal waves of the second vertical mode in a stratified lake, Limnol. Oceanogr., 32, 29-42, 1987. 